\title{
Gender Perceptions: Employer Branding Through Attractiveness, Job Characteristics and Organizational Attributes
}

\author{
Summer Aslam ${ }^{*}$, Cordelia Mason², Asma Zakria ${ }^{3}$, Mohd Farid ${ }^{4}$ \\ ${ }^{1}$ Department of Human Resource Management, University of Kuala Lumpur, Jalan Sultan Ismail, Kuala Lumpur, MALAYSIA \\ ${ }^{2}$ Dean, Management Sciences, University of Kuala Lumpur, Jalan Sultan Ismail, Kuala Lumpur, MALAYSIA \\ ${ }^{3}$ Lecturer, Management Sciences, University of Kuala Lumpur, Jalan Sultan Ismail, Kuala Lumpur, MALAYSIA \\ ${ }^{4}$ Marketing Department, University of Kuala Lumpur, Jalan Sultan Ismail, Kuala Lumpur, MALAYSIA \\ *E-mail for correspondence: summerhrm@gmail.com
}

Received: Jan 23, 2015;

Accepted: Feb 27, 2016;

Published: May 21, 2016

Source of Support: Nil

No Conflict of Interest: Declared

\begin{abstract}
The novelty of employer branding is undeniable in HR practices. However, the pair studies are also found in employer branding with the perception of gender. A gender difference is said to occur when male and female react differently in perceptions. In Pakistan, human capital is an inadequacy in bank jobs and female less appearance in the sector creates more shortage of skilled employees. However, the results reported have given an insignificant difference between male and female in the perception of employer branding. Moreover, the gender disparity has no borders, so re-justification is an admirable in another region. Hence, a significant relationship exists between employer branding and intention to apply. Intention to apply is a central dealing with recruitment as appears with the wish for of submitting a job application. Furthermore, the wider applicant pool can achieve with employer branding. Employers can persuade to potential employees through attractiveness, unique organizational attributes and job characteristics. Concluded, banks in Pakistan can increase a wider applicant pool with the implementation of employer branding. Data Analysis was done by using SPSS and smart PLS. Future recommendations and implications are at the end.
\end{abstract}

Keywords: Employer Branding, Intention to apply, Gender Difference, Banking Sector

\section{INTRODUCTION}

Gender is a collectivity of male and female. Their roles are undeniable as participation in social activities, households, economic strata and political levels. With regards to a job market, where the collectivity of male and female is crucial as diversity. However, a female work participation, compensation and job choices have been debating for a long time. Nonetheless, the issues of their work participation are not same in each state because of different scenarios. In developing countries, Pakistan, is one of those countries where the female work participation is not like developed countries and even not in line with developing countries. They do not enter the job market after the completion of their studies. They were seen choosier in the selection of employment. According to the labor force survey report (2013), their participation is not satisfactory in comparatively South and East Asian countries as shown in Table 1.1. More participation has been seen in certain fields like health sciences and education (Isran, \& Isran,2012). However, their participation has seen lower in the banking jobs, the pair appearance of them has started in the last few years. Where the banking sector is in high need of potential human capital (male and female both), the female less participation in bank jobs increases the demand for of potential employees in the sector. It is the most vital service sector in Pakistan. Despite the finest sector, it is plagued by many problems (Hassan et al., 2012). After the advent of multinational banks and begin of Islamic banking, the fierce competition has emerged among banks (Bowra et la., 2012; Hassan et a., 2012; Rashid, E Rashid, (2012). Employee turnover is the critical issue and refills the vacancies are too difficult in banks (Bowra et al., 2012). The fresh graduates have not been giving attention to banks for applying for a job due to the social conflict (interest) and contradicted believes. Their tendency to join is not admirable (Bowra et al., 2012). Nonetheless, intention to apply is the main firewood in recruitment (Aslam, 2015; Saini et al., 2013). However, the most significant factor employer branding has recently introduced for intention to apply in the literature (Saini et al., 2013).

Globally, a job market has attained greater attention with a scarcity of human capital (Ployhart, 2006). Organizations are facing tremendous challenges to attract the potential employees (Franca, \& Pahor, 2012). Employee turnover is a core issue in organizations as not has easy to refill the vacancies even despite high unemployment (Arachchige 
\& Robertson, 2013). Even in the tough economy days, organizations are facing the inadequacy of human capital in developing and developed countries both. In developing countries, human capital is taking flight speedily affecting brain drain. Pakistan is one of those countries whose potential employees are migrating from the country. According to Dilshad, (2013) author that World Bank reported (2011) of 4.7 million immigrants moved out of Pakistan. Nonetheless, all sectors are affecting, and organizations in Pakistan face the shortage of human capital. Especially service zone where employee turnover is a core matter (Bajwa, 2014).

\section{Overview of Human Capital -Brain Drain (Pakistan)}

Human capital is taking flight and expected to continue rising. Overall, the state (Pakistan) is in great need of skilled and talented human capital to compete in the global era (Khurram et al.,2013). Currently, Pakistan is placed in the 4th rank compared to 7th in 2011 in the countries affected by the skilled brain drain in the world. The migration rate of 4.7 million skilled workers shows that the employment offered by the organization in country is not attracting the young talents (Dilshad, 2013). Disability to attract fresh applicants for job postings creates a concern for most employers (Baloch \& Awan, 2013).

\section{LITERATURE REVIEW}

The concept employer branding is closely related to employer attractiveness. Employer branding is marketing, among the employers to make an attractive image in the minds of its potential associates (Aslam, 2015; Saini et al., 2013). Following that, an employer branding is humanizing the image in the minds of potential associates. In the digital world, human and brand are two close contacts as a brand and reputation are on the top of the minds of everyone. When people go to shopping, the first query is about "brand". Similarly, a job market is going to become merged with the word "brand". Similarly, Saini et al.(2013 expressed their opinion that employer branding relates to that what employers offer to employees. Potential employees always look at the green pastures on their compensation, organizational culture and job characteristics. Organizational attributes and job characteristics make the sense of uniqueness about employer image. It differentiates to an employer in comparison to other employers in a job market. According to Gomes \& Neves, 2011) the attraction to organization is influenced by organizational attributes and job characteristics. They conclude that job characteristics (JC) and organizational attributes (OAT) develop the general perceptions in the minds of potential employees further, the job characteristics (JC) and organizational attributes (OAT) are critical to an understanding of potential employee's intentions.

The perception of the employees might be different based on gender, work experience, academic levels. The gender difference has been seen significant or insignificant in marketing. For a long time, female and male participation in a job market is highly distinguishable in Pakistan. Therefore, this study comes up with the perception of employer branding in against to gender. The model of employer branding contains three dimensions, namely the employer attraction (EA), organizational attributes (OAT) and job characteristics (JC). These three dimensions (EA) (OAT) and (JC) of employer branding are unobserved in perspective to the banking sector, Pakistan. Hence, researchers formulate the following hypotheses.

$\mathrm{H}_{1}$ There is a significant relationship between EB and ITA. $\mathbf{H}_{1 \mathrm{~A}}$ There is a significant relationship between EA and ITA. $\mathbf{H}_{1 \mathbf{b}}$ There is a significant relationship between OAT and ITA. $\mathbf{H}_{1 \mathbf{c}}$ There is a significant relationship between JC and ITA.

$H_{1 D}$ There is a significant difference between Male and Female with respective to the perception the EB.

\section{Methodology}

This study holds the quantitative method. Researchers use 7 point Likert scale in questionnaires. The questionnaires distributed by hand to 60 respondents. All respondents were dealing with commerce and business studies in public and private universities located in Lahore (Punjab). Ten questionnaires were incomplete. For remaining 50 questionnaires, the SPSS (20.0) and Smart PLS 3.0 were used for data analysis. Smart PLS was used as it better for latent variables scores even small sample size. The reliability was satisfactory with high Cronbach Alpha for each latent variable $\mathrm{EB}=0.896$, ITA $=0.910$. Employer branding was seen positively significant for potential employee's intention to apply. Therefore, H1 was accepted. A figure 1.2 indicated with $\beta=0.627$ that means employer branding 62 percent contributes to the potential employee's intention. The sub-hypotheses were also tested. The results of sub-hypotheses were accepted at $p$-value $<0.000$. The $\beta$-value for all of these dimensions was found supportive. An independent t-test was also done to observe the gender difference. This study contains male and female. As a result of an independent $t-$ test, the mean scores were similar, and found that there is no difference in mean scores between male and female at p $>0.05$. The reliability report, results of figures and table are given in Appendix-A and B.

\section{Gender Difference-Preference to Bank}

In descriptive part, the variable first choice was included in the questionnaire. The variable first choice was the most vital for this study as most related to the specification of intention to apply for a job. Respondents were asked three choices with respective to Foreign bank, Islamic Bank \& Conventional bank. The highest inclinations were seen in the male for foreign Bank and low for the conventional Bank. Where male gave high scored to a foreign Bank, unlikely female preferred to Islamic Bank. However, here still conventional Bank attained the lowest rank among of male and female as well. 


\section{Conclusion And Recommendation}

The primary focus was to monitor the relationship between employer branding and intention to apply for a job perspective to banking sector of Pakistan. The results are positive and significant of $\mathrm{H}_{1}$ and sub-hypotheses $\mathrm{H}_{1 \mathrm{~A}}$, $\mathrm{H}_{1 \mathrm{~B}}$ and $\mathrm{H}_{1 \mathrm{c}}$ as well.

Potential employees look at the employer image as a signal on a rich organizational culture, good pay, and job characteristics. Here, pay is a signal where inflation exists in the country. Pakistan in one of those countries where inflation is high. Pay can helpful to overcome the inflation that further leads to intention to apply. The adjustment of these factors should be according to economy of Pakistan (Bowra et al., 2013). To apply for either a job or remove, potential employees look at the organizational culture before becoming a member of the applicant pool. According to Oladipo et al.(2013) competitive culture and salary are meaningful for potential employees. Authors Mathews \& Karulkar (2013) also expressed the opinion that salary is the reason to attract the potential employees.

The potential of human capital in Pakistan is ready to be professionalism with integration of training and development, autonomy, diversified skills and independence in work. The satisfaction of the independence in work is motivating for self-employment among youth. Concluded, potential employees look up to the banking sector in providing to them better salary, working environment and independence at work. After graduating, working place is considered the establishment to be groomed in skills, learning and development.

Furthermore, the cultural inhibitions exist in Pakistan that appears in the distraction of employment of females in the banking sector. Further, man is considered only the breadwinner in the state. According to social influence and cultural inhibitions, there are different schools of thoughts in society. However, it is not unchanged in all regions and provinces. Based on the middle class and higher class, Punjab and Sindh have a female participation better than KPK and Balochistan. Punjab (Rural and Urban) is the highest tolerance province of female participation in a job market.

Even better mobility but still not sufficient in comparison South and East Asian countries. Nevertheless, with such kind of job market, organizations in Pakistan have to focus more on their employer image. With the having employer image, cultural and social influence might be less hindrance in the female participation in bank jobs. The limitation of this study is a small sample size. Therefore, the results cannot be generalized. Based on the constraint, the replication of this study is encouraged in the future.

\section{IMPLICATIONS}

The findings of this study show significantly shifting of human capital in attracting of employer branding. The banking sector has a fierce competition and the presence of competition force to implement the employer branding. Banking sector should accurately define HR practices in recruitment. The role of HR practices must be close to employer branding in attracting to potential employees. Employer branding will help to executives of the banks to attain a wider applicant pool that will further lead to obtaining the professional approach.

\section{REFERENCES}

Arachchige, B., \& Robertson, A. (2013). Employer Attractiveness: Comparative Perceptions of Undergraduate and Postgraduate Students.Sri Lankan Journal of Human Resource Management, 4(1), 33-48.

Aslam, S. (2015). Employer Branding and Intention to Apply by Usage of Social Media in Banking Sector, Pakistan. International Journal of Scientific \& Engineering Research, 6(5), 400-405.

Bajwa, A. (2014). Pakistan Employment Trends 2013.

Bajwa, E., Yousaf, M., \& Rizwan, M. (2014). Employee Turnover Intention in services sector of Pakistan. International Journal of Human Resource Studies, 4(2), 164-180.

Baloch, A. H., \& Awan, S. H. (2013). Impact of employer brandequity promotion for effective talent recruitment of fresh graduates in Pakistan. African Journal of Business Management, 6(44), 10906-10924. Retrieved from DOI: 10.5897/ AJBM11.2384

Bowra, Z., Sharif, B., Saeed, A., \& Niazi, M. (2012). Impact of human resource practices on employee perceived performance in banking sector of Pakistan. African Journal of Business Management, 6(1), 323-332.

Dilshad, W. (2013). Impact of Workers' Remittances on Economic Growth: An Empirical Study of Pakistan's Economy. International Journal of Business and Management, 8(24), 126-131.

Franca, V., \& Pahor, M. (2012). The Strength of the Employer Brand: Influences and Implications for Recruiting. Journal of Marketing and Management, 3(1), 78-122.

Gomes, D., \& Neves, J. (2011). Organizational attractiveness and prospective applicants' intentions to apply. 40(6), 684-699.

Hassan, Y., Din, K., Mir, Z., Ahmad, K., Mateen, A., Ahmad, W., \& Nasir, A. (2012). Job Satisfaction in Private Banking Sector of Pakistan. Global Journal of Management and Business Research, 11(12), 84-94.

Isran, S., \& Isran, M. (2012). Low Female Labour Participation in Pakistan: Causes and Consequences. Pakistan Journal of Social Sciences,32(2), 453-468.

Khurram, M. I., $\quad$ Butt, T. M., Shahbaz, B., Ahmad, S., Rahman, M. A., Shakoor, U., \& Rizwan, M. (2013). Effects of unemployed rural youth on rural development (ORIC-1303). African Journal of Agricultural Research, 8(44), pp. 55625571. Retrieved from DOI: 10.5897/AJAR2013.7689.

Mathews, E., \& Karulkar, P. (2013). Perception of MBA Students on Employer Branding. International Indexed \& Refereed Research Journal,5 (42), 61-63. 
Obaid, A. (2013). Changes in the pay structures and systems in the banking sector of Pakistan: Implications for a differentiated workforce and the employee psychological contract. 1-373.

Oladipo, T., Iyamabo, J., \& Otubanjo, O. (2013). Employer Branding: Moulding Desired Perceptions in Current and Potential Employees.Journal of Management and Sustainability; Vol. 3, No. 3; 2013, 3(3), 55-65.

Ployhart, R. (2006). Staffing in the 21st Century: New Challenges and Strategic Opportunities .Journal of Management, 6(11), 868-898.
Rashid, S., \& Rashid, U. (2012). Work Motivation Differences between Public and Private Sector. American International Journal of Social Science, 1(2), 24-33.

Saini, G., Rai, P., \& Chaudhary, M. (2013). What do best employer surveys reveal about employer branding and intention to apply? Journal of Brand Management, 1-17. doi:10.1057

\section{APPENDICES}

Appendix-A

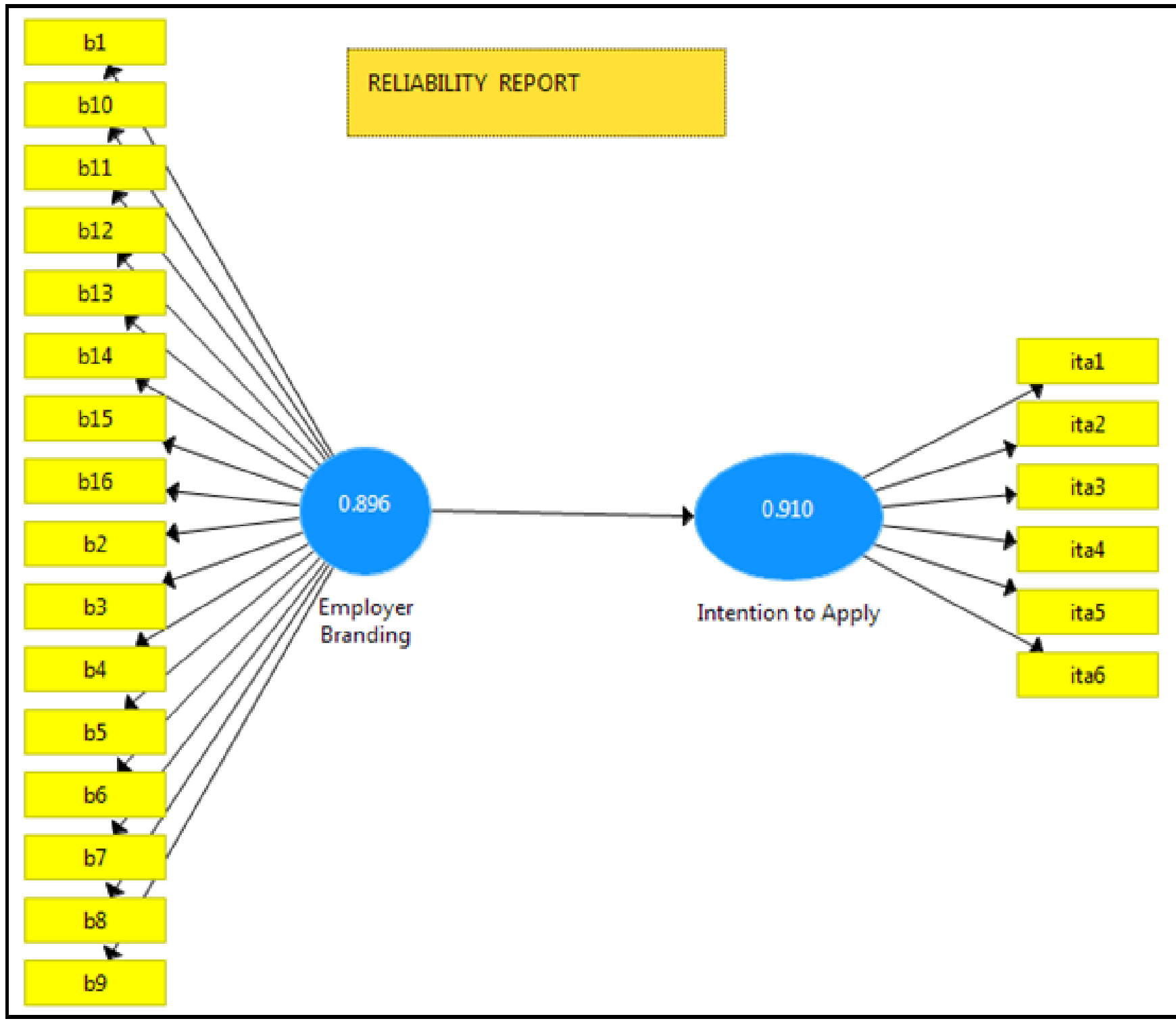

Figure 1:

Reliability Report (EB-ITA) 


\section{Appendix -A continue}

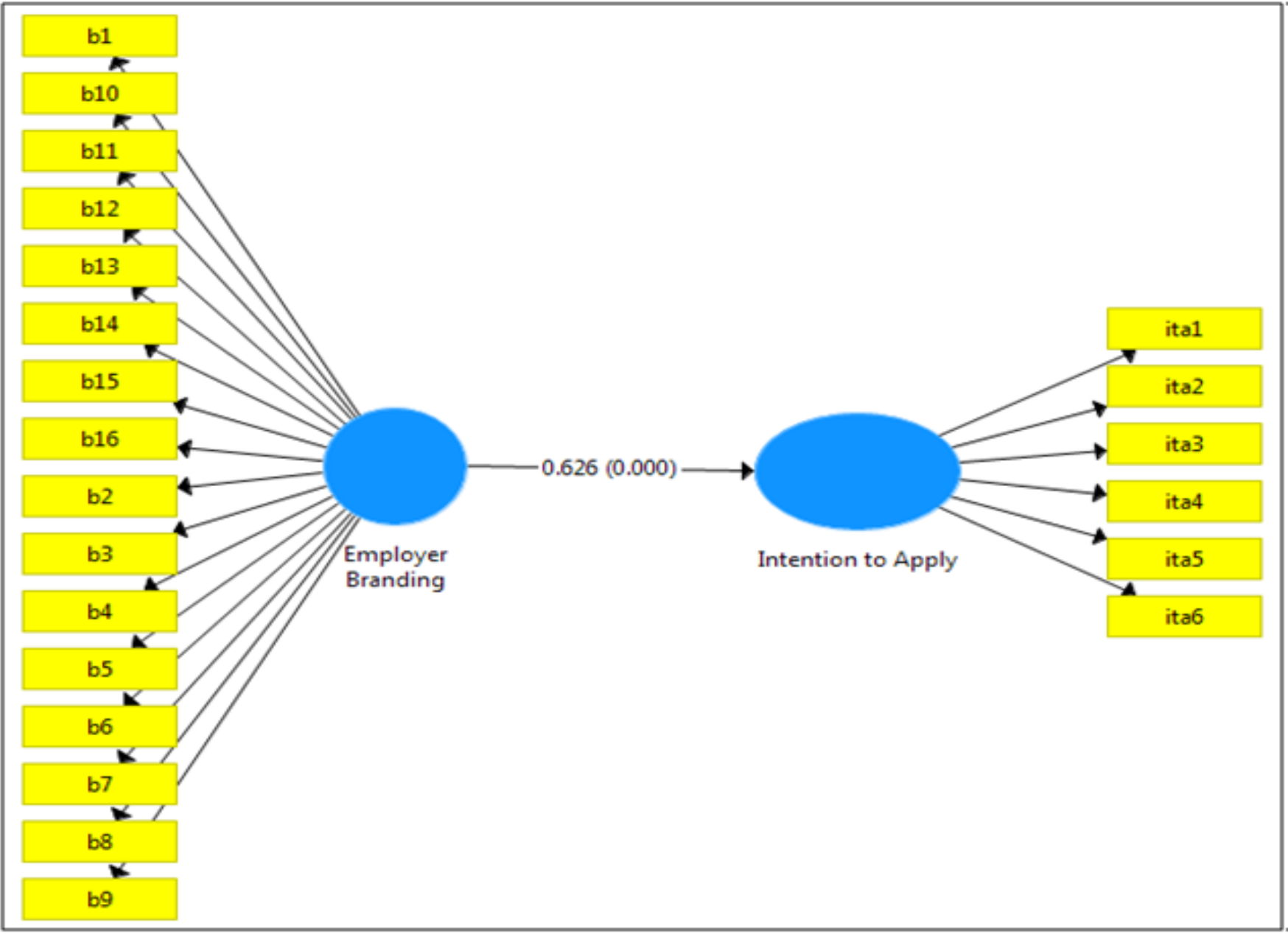

Figure 1.2

\section{Appendix-B}

Table 1.1: Female and Male Employment comparison with South and East Asia

\begin{tabular}{|c|c|c|c|c|c|c|c|c|c|}
\hline 15-24 Years & 2001-2002 & 2003-2004 & 2005-2006 & 2006-2007 & 2007-2008 & 2009-2010 & 2008-2009 & 2010-2011 & 2012-2013 \\
\hline Male & 61.8 & 62.7 & 66.1 & 64.2 & 62.3 & 61.4 & 61.3 & 59.5 & 58.2 \\
\hline Female & 11.8 & 13.7 & 16.8 & 16.6 & 17.1 & 18.3 & 18.8 & 18.8 & 18.4 \\
\hline South Asia (15+) & & 2005 & 2006 & 2007 & 2008 & 2009 & 2010 & 2011 & 2012 \\
\hline Male & & 79.9 & 79.8 & 79.6 & 79.1 & 78.5 & 78.5 & 78.5 & 78.5 \\
\hline Female & & 35.3 & 34.7 & 33.5 & 32.5 & 31.3 & 30.2 & 30.3 & 30.4 \\
\hline East Asia (15+) & & & & & & & & & \\
\hline Male & & 76.9 & 76.8 & 76.8 & 76.1 & 75.8 & 75.8 & 75.6 & 75.5 \\
\hline Female & & 65.7 & 65.7 & 65.6 & 64.8 & 64.5 & 64.6 & 64.3 & 64.1 \\
\hline
\end{tabular}

Table 1.2: Path Coefficient of Dimensions of Employer Branding

\begin{tabular}{lll}
\hline & $\mathrm{JC} \longrightarrow \mathrm{Org} \longrightarrow \mathrm{ITA}$ & Employer Attractive $\longrightarrow$ ITA \\
\hline$\beta$ & $.44^{* * *} \longrightarrow$ & \\
$\beta$ & $.53^{* * * *}$ & \\
$\beta$ & & $0.43^{* * *}$ \\
\hline & & $--0--$
\end{tabular}




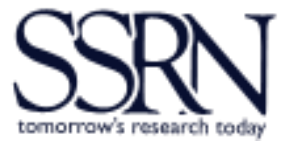

Social SCIENCE RESEARCH NETWORK

2171 Monroe Avenue, Suite 203, Rochester, NY 14618, USA

http://www.ssrn.com/en/

AJTP Link: http://www.ssrn.com/link/American-Journal-Trade-Policy.html 